\title{
Discriminability of the postictal state produced by electroconvulsive shock in rats
}

\author{
DONALD A. OVERTON, MARIO A. ERCOLE, and PURABI DUTTA \\ Department of Psychiatry, Temple Medical School, Philadelphia, Pennsylvania 19140 \\ and \\ Eastern Pennsylvania Psychiatric Institute, Philadelphia, Pennsylvania 19129
}

\begin{abstract}
Rats were trained to escape from shock in a T-maze. Repeated training sessions were administered with a right turn required after electroconvulsive shock (ECS) and a left turn after no treatment. Results were as follows: (1) Postictal state was readily discriminated 2-10 min after ECS. (2) Discriminability attenuated by $60 \mathrm{~min}$ and was absent 2-7 days after ECS. (3) Severe footshock just prior to ECS did not alter ECS discriminability. (4) No simple interchangeability between cueing effects of drugs and ECS was found. The postictal state is discriminated as rapidly as are centrally acting drugs. Similar mechanisms may be involved.
\end{abstract}

Responses learned by rats during the postictal period following electroconvulsive shock (ECS) are sometimes state-dependent. Performance of such habits is optimal if ECS is readministered prior to retention testing, and less efficient if no ECS precedes testing (NECS condition). Both whole-brain ECS and kindled convulsions elicited by amygdala stimulation will produce the effect (McIntyre \& Reichert, 1971; Thompson \& Neely, 1970). This finding is of considerable significance, since ECS is a nonpharmacological manipulation. Although weak statedependent learning (SDL) has been observed with certain naturally occurring drive and emotional states (Huang, 1973; Otis, 1956; Peck \& Ader, 1974), strong SDL has been previously observed only with drugs.

Unfortunately, published results lead to somewhat conflicting conclusions about the properties of ECSinduced SDL. Thus, postictal SDL has been reported to attenuate rapidly during the $\mathbf{3 0} \mathrm{min}$ following ECS and to be absent at $24 \mathrm{~h}$ (Gardner, Glick, \& Jarvik, 1972; Thompson \& Neely, 1970). However, if ECS is preceded by footshock, then SDL is reported still present 5 days after ECS (DeVietti, Mayse, \& Morris, 1974). Even when ECS is administered immediately after training, consolidation is claimed to take place during the postictal period producing state-dependent engrams (Thompson \& Neely, 1970). Also, scopolamine and physostigmine have been reported to mimic the ECS state (Gardner et al., 1972), although in pilot experiments we failed to observe this effect.

Virtually all prior ECS SDL studies have utilized the 2 by 2 experimental design in which four groups of animals were trained and subsequently tested for

Supported in part by NIDA Grant DA00301 and by NIMH Grant MH25136. The authors gratefully acknowledge the technical assistance of David George and Marcia Etheridge. retention under conditions NECS-NECS, NECS-ECS, ECS-NECS, and ECS-ECS, respectively. Although this experimental design is widely used for the study of SDL, it has severe shortcomings (Overton, 1974). In short, the 2 by 2 design allows treatment effects other than SDL to be confused with SDL so that a mistaken attribution can be made regarding the actual causes of experimentally observed effects.

The purpose of the present studies was to reinvestigate the SDL effects of ECS using a modified drug discrimination paradigm. Such procedures appear to measure the effects responsible for SDL, often have a greater sensitivity than the 2 by 2 design, and have, to date, produced more quantitatively replicable results than 2 by 2 experiments. In the present experiments, rats were repeatedly trained to perform one response during the postictal period and a different response when no ECS was administered. Unfortunately, this paradigm requires repeated administration of ECS and some effects of ECS may alter with repeated administrations (Wiener, 1970). Nonetheless, other effects (e.g., the convulsion) do not change greatly, and we thought that useful data could be obtained with these procedures.

\section{GENERAL METHODS}

\section{Subjects}

Experimentally naive adult male Long Evans strain hooded rats were used. They were housed 2-3 per cage and weighed 200-300 g at the beginning of testing. All rats were purchased from Blue Spruce Farms, and changes in strain were not noted during the 3-year duration of the experiments. Most individual experiments involved comparison between groups of animals purchased at the same time.

\footnotetext{
Apparatus

Rats were trained to escape from unavoidable shock in a modified T-maze which has been previously described in detail (Overton, 1966). The maze floor consisted of steel rods electrified thoughtout the maze, except in the goalboxes, by a Grason-
} 
Stadler shock scrambler (1.6 mA). The maze walls were $24 \mathrm{in}$. high and painted flat gray. The top of the maze was open, and the maze was illuminated by a $150-\mathrm{W}$ spotlight bulb placed $3 \mathrm{ft}$ above the choice point. Either goalbox could be made inaccessible by a barrier door which was not visible from the choice point. Electroconvulsive shock was applied via alligator clips through the dampened ears. A $1,500-\mathrm{V}$ ac transformer in series with a resistor yielded a $75-\mathrm{mA}$ RMS sine wave $60-\mathrm{Hz}$ current with a duration of $150 \mathrm{msec}$. Rats were placed in a wastebasket while receiving ECS and returned to their home cage during the interval before training.

\section{Training Procedures}

Rats were allowed to explore the T-maze for $20 \mathrm{~min}$ before training began. Training involved repeated training sessions. Each session consisted of 10 individual trials and lasted 5-10 min. On each trial, the rat was placed in the start compartment facing the choice point, with the shock already turned on, and allowed to run freely in the maze until it reached and remained in the accessible goalbox. The intertrial interval approximated $30 \mathrm{sec}$ and rats were trained in squads of three. The interval between successive sessions was different for each experiment, as described below, but never less than $24 \mathrm{~h}$. The required T-maze choice alternated during successive sessions, as did the ECS treatment. Hence, rats were required to turn left (or right) during Sessions 1, $3,5 \ldots$ when untreated and were required to turn right (or left) during Sessions 2, 4, $6 \ldots$ when treated with ECS.

\section{Data Analysis}

The rats' choice on the first trial of each session appeared to indicate whether the rat could select its response on the basis of the imposed treatment condition. An analysis of variance (ANOVA) for repeated measures (Edwards, 1967) was used to compare the first trial performance of various groups and to determine whether learning occurred. Another measure of performance was derived for each animal from the number of training sessions before criterion performance was achieved (STC): a criterion of eight correct first-trial choices during 10 successive training sessions was adopted. STCs were logarithmically transformed before computations to normalize their distribution. Also, the number of errors on the first trial of Training Sessions 1-30 was used as an index of performance.

\section{EXPERIMENT I TIME COURSE}

This experiment was designed to measure the degree of postictal discriminability at intervals up to $2 \mathrm{~h}$ after ECS. It sought to determine whether discriminability of the postictal state attenuated rapidly with time or persisted for longer intervals, and whether the return from the postictal dissociated state to the normal state was a continuous process or involved a discrete transition between the two states.

\footnotetext{
Method

Seven groups of rats received an alternating series of 10-trial training sessions with left-turn sessions preceded by ECS and with no treatment preceding right-turn sessions. The independent variable in this experiment was the time interval between the 75-mA ECS and the first trial of the ECS training session. This ECS-to-training interval was $2.5,5,10,20,30,60$, and $120 \mathrm{~min}$, respectively, in the seven groups. The interval between successive sessions was 24 or $48 \mathrm{~h}$, with $48 \mathrm{~h}$ separating an ECS session from the succeeding NECS session; in this way, we allowed
}

$48 \mathrm{~h}$ for the dissipation of ECS effects without unduly prolonging the training procedure. Training was continued until criterion performance was reached or until 60 sessions, whichever came first. Deaths due to spinal shock were frequent, especially during the first few ECS treatments. A total of 37 rats completed the training regimen with individual group Ns varying from 3 to 9 .

Three control experiments were run. One control group was earclipped $5 \mathrm{~min}$ before treatment sessions with no ECS applied, and was not earclipped before NECS sessions. A second control group received a $1-\mathrm{sec}, 75-\mathrm{mA}$ shock applied between the left and right rear paws 10 min before treatment sessions, and received no treatment before alternate NECS sessions, in order to see if they could discriminate the sequelae of the ECS shock when it was not applied to the brain. Finally, half of the rats which had a 10-min interval between ECS and training were earclipped before NECS training sessions as well as when ECS was applied.

\section{Results and Discussion}

No rats in either control group achieved criterion performance within 60 sessions. Also, 10-min rats discriminated ECS vs. NECS with equal ease, irrespective of whether ear clips were applied before NECS sessions.

Performance of the seven experimental groups is shown in Figure 1, where geometric mean sessions to criterion (STC) is plotted as a function of ECS-totraining interval. (An STC of 60 was used for rats that failed to reach criterion.) The regression line through the data points for each group was computed from logarithmically transformed values for both sessions to criterion and interval. Its slope $(\mathrm{m}=0.6)$ differs significantly from zero $(r=.59, \mathrm{p}<.01)$.

The data suggests that postictal discriminability attenuates rather rapidly with time, and that the decrease in dissociation takes place in a continuous fashion rather than as a discrete step. The low value of STC in the $2.5-\mathrm{min}$ group is comparable to that produced by high doses of drugs having strong SDL effects, and is in agreement with the report of virtually total dissociation produced by kindled convulsions in this task (McIntyre \& Reichert, 1971). Higher STCs were observed with intervals of $10-30 \mathrm{~min}$. In drug SDL experiments, this degree of discrimin-

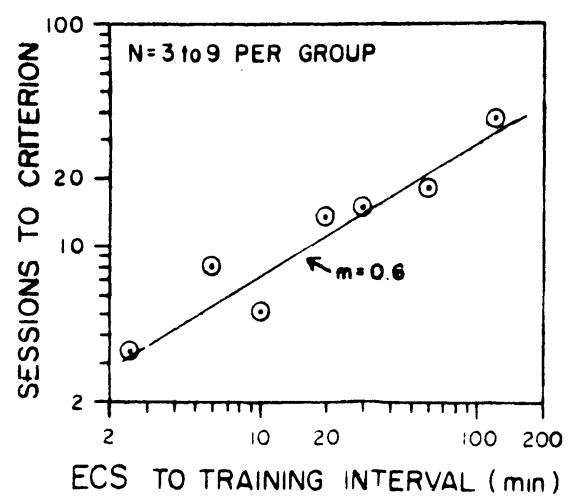

Figure 1. Discriminability of the postictal state at various intervals after ECS. $X$-axis is interval between ECS and training session. $Y$-axis is geometric mean sessions to begin criterion performance. 
ability has been predictive of SDL amnesias in passive avoidance and shuttlebox tasks, reflecting an apparently greater sensitivity of those tasks to dissociative effects. Hence, the present results are in accord with those of Gardner et al. (1972) and Thompson and Neely (1970), who reported amnesias at intervals of 10-30 min in such tasks.

It should be noted that the NECS sessions in this experiment took place only $48 \mathrm{~h}$ after ECS. Some effects of ECS persist longer than 48 ' $h$ (Nielson \& Flemming, 1968). Hence, rats in this experiment may have learned a "highly abnormal vs. a less abnormal" discrimination, rather than the intended normal vs. abnormal discrimination.

\section{EXPERIMENT II PROLONGED ECS EFFECTS}

Experiment II was essentially a replication of Experiment I, except that a longer interval was allowed to elapse between each ECS and the following NECS training session so that the effects of ECS could dissipate. In addition, discriminability of the postictal state was tested at intervals up to 7 days after ECS.

\section{Method}

Seven experimental groups of rats received a series of 10-trial training sessions with alternating ECS and NECS conditions as in Experiment I. The interval between ECS administration and the ECS training session ranged from $10 \mathrm{~min}$ to 7 days, as shown in Figure 2. Two training sessions were scheduled in each 3-week period. Specifically, within each 3-week cycle, NECS training was conducted on Day 1; ECS was administered on Day 4; ECS training took place on Days 4 through 11, depending on the required interval between ECS and training; the animals then rested through Day 21, after which the cycle was repeated. One "earclips" control group was trained; NECS training was conducted on Day 1 of the cycle, earclips were applied on Day 4 with no ECS delivered, and "ECS" training took place $24 \mathrm{~h}$ later on Day 5. In all eight groups, training was arbitrarily discontinued after 40 training sessions (60 weeks) irrespective of whether or not discriminative control had appeared. Animals that died during the first 20 weeks were replaced. A total of 49 rats (4-6 per group) completed the training regimen.

\section{Results and Discussion}

Differential responding by each animal was quantified with two indices; sessions to criterion and first trial errors. The sessions to begin criterion performance was computed as in Experiment I, except using STC $=40$ in cases where animals failed to discriminate within the period of training. The number of first-trial errors during Sessions 1-30 was also computed. Both variables are plotted in Figure 2.

No animals in the earclips control group achieved criterion performance; mean first-trial errors were 20.8 and first-trial performance remained essentially uniform throughout the course of training. Groups trained with long ECS-to-training intervals $(2,4$, and
7 days) showed STC and first-trial error scores comparable to those of the control group, suggesting that discriminable effects of ECS did not persist 2-7 days after the ECS treatment. In all these groups, performance during Sessions 1-16 improved, as if the animals were acquiring a discrimination, and one animal in the 7-day group transiently achieved criterion performance. Subsequently, performance tended to deteriorate to below the level of the control group. The reason for the initial trend towards improved performance is unclear. Performance never rose above the random level, but was simply not as far below random as in the control group. Hence, simple response disorganization may have produced the effect.

In the 24-h group, two animals rapidly acquired discriminative performance which they maintained for about 15 sessions before relapsing to subrandom performance. Although the other four animals did not show clear differential responding, overall group performance differed almost significantly from that of the control group ( $\mathrm{p} \cong .06$ ). Hence, our results suggest that some degree of discriminability was present $24 \mathrm{~h}$ after ECS in this group. Loss of discriminative control was observed in both animals that initially acquired a discrimination. This may indicate that ECS lost its ability to produce longlasting dissociative effects when repeatedly administered.

The three groups trained with short ECS-totraining intervals $(10,30$, and $120 \mathrm{~min})$ made fewer first-trial errors than did the earclips control group $(p \leqslant .01, .01, .05)$. Performance by these groups did not differ significantly from that of the comparable groups in Experiment I.

To summarize, SDL was observed with short ECS-

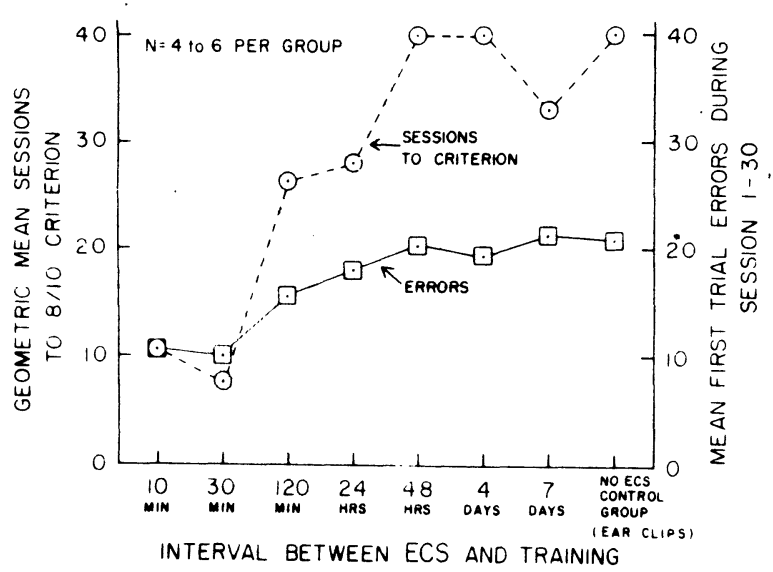

Figure 2. Discriminability of the postictal state at various intervals after ECS when training sessions are separated by long intervals $(1 / 2-21 / 2$ weeks). $X$-axis is interval between ECS and the immediately following training session. Dotted line is geometric mean sessions to begin criterion performance. Solid line is mean first-trial errors during Sessions 1-30. 
to-training intervals, as in Experiment I. With a 24-h interval between ECS and training, weak SDL effects were observed. With ECS-to-training intervals of 2 days or greater, discriminative control did not appear.

\section{EXPERIMENT III TRANSFER TO DRUGS}

Using a passive avoidance task, Gardner et al. (1972) observed that the SDL effects of the postictal state appeared to mimic those of certain drugs, and vice versa. This suggests that ECS and drugs induce SDL via the same mechanism-an important conclusion. In the present experiment, we tested whether the discriminable effects of ECS and selected drugs were interchangeable in the drug discrimination paradigm.

\section{Method}

The transfer test method was used. Trained rats received test trials during which both goalboxes were accessible..These test trials under novel states were interspersed among continuing training sessions under the original training conditions. During such test trials, the rat's choice apparently indicates which of the training conditions is more closely mimicked by the test condition (Overton, 1966).

Eight of the rats from Experiment I, which had previously learned to discriminate ECS vs. NECS with intervals of 10-20 min, were used for cross-testing to the drugs listed in Table 1 . In addition, 17 rats were trained to discriminate pentobarbital $15 \mathrm{mg} / \mathrm{kg}$ vs. no drug. After this discrimination was well learned, they were given ECS test trials with various intervals between ECS and testing, as listed in Table 1. Not all rats were tested under all conditions.

Statistical evaluation of test-trial performance was accomplished by computing the cumulative binomial distribution. A priori probability was computed by averaging (across rats) the first-trial performance during 10 training sessions that closely preceded and followed the test session. The cumulative binomial was used to determine the likelihood of the performance observed in the test trial. The $\mathrm{p}$ values obtained by this method are influenced both by test performance and by the baseline level of training performance.

\section{Results and Discussion}

Table 1 shows that scopolamine, physostigmine, carbacol, and arecoline significantly failed to substitute for ECS in rats trained to discriminate ECS vs. NECS. The selected dosages of physostigmine, carbacol, and arecoline were close to the maximum at which the animals could function behaviorally. The dose of scopolamine has been shown to produce maximal SDL effects, even though higher doses can be administered without disabling the animal (Overton, 1971). As test performance did not differ with pentobarbital 10,15 , and $20 \mathrm{mg} / \mathrm{kg}$, data for the three doses were pooled. Pentobarbital $10-20 \mathrm{mg} / \mathrm{kg}$ did elicit the ECS response, suggesting that pentobarbital mimicked the discriminable effects of ECS. However, pentobarbital-trained rats did not make
Table 1

Transfer Test Results

\begin{tabular}{lccccc}
\hline \multicolumn{2}{c}{ Rats Trained with ECS vs. No ECS (Delay $=10-20 \mathrm{~min})$} \\
\multicolumn{1}{c}{$\begin{array}{c}\text { Dose } \\
\text { Test Drug }\end{array}$} & $\begin{array}{c}\text { Delay Number } \\
\text { (mg/kg) }\end{array}$ & $\begin{array}{c}\text { ECS } \\
\text { (min) } \\
\text { of Tests }\end{array}$ & Turns & Signif. \\
\hline Pentobarbital & $10-20$ & 15 & 22 & 85 & $\mathrm{~b}$ \\
Scopolamine & 5 & 20 & 11 & 63 & $\mathrm{a}, \mathrm{b}$ \\
Physostigmine & 1 & 5 & 9 & 22 & $\mathrm{a}$ \\
Carbacol & .8 & 7 & 6 & 50 & $\mathrm{a}$ \\
Arecoline & 10 & 7 & 9 & 47 & $\mathrm{a}, \mathrm{b}$ \\
\hline
\end{tabular}

Rats Trained with Pentobarbital 15 vs. No Drug

$($ Delay $=15 \mathrm{~min})$

\begin{tabular}{ccccc}
$\begin{array}{c}\text { Test } \\
\text { Condition }\end{array}$ & $\begin{array}{c}\text { Delay } \\
\text { (min) }\end{array}$ & $\begin{array}{c}\text { Number } \\
\text { of Tests }\end{array}$ & $\begin{array}{c}\text { Percent } \\
\text { Drug Turns }\end{array}$ & Signif. \\
\hline ECS 75 mA & 5 & 12 & 29 & a \\
ECS 75 mA & 10 & 16 & 50 & a, b \\
ECS 75 mA & 15 & 10 & 45 & a, b \\
ECS 75 mA & 20 & 10 & 50 & a, b \\
\hline
\end{tabular}

Note. $a=$ significantly fewer $D$ turns than on first trials of proximal $D$ training sessions $(p<.05) . b=$ significantly more $D$ turns than on first trials of proximal $N$ training sessions $(p<.05)$.

drug choices when tested postictally. Hence, although pentobarbital mimicked ECS, the converse was not true. One-way substitutions of this type have been reported previously, and are not at present understood (Overton, 1966, 1974). Gardner et al. (1972) interpreted their data as showing that scopolamine SCL was mimicked by ECS and that ECS SDL was mimicked by physostigmine. Also, Davis, Thomas, and Adams (1971) obtained results suggesting that physostigmine might mimic the SDL effects of ECS. Interchangeability between the SDL effects of ECS and of cholinergic drugs was not observed in the present experiments.

\section{EXPERIMENT IV EFFECTS OF FOOTSHOCK PRIOR TO ECS}

ECS aftereffects and even some aspects of the induced convulsion can be altered if footshock (FS) precedes the ECS (Chorover \& DeLuca, 1969; Kesner \& D'Andrea, 1972; Pinel, 1971). As regards SDL, DeVietti et al. have observed marked differences between the SDL effects of FS + ECS and those consequent to ECS alone (DeVietti \& Larson, 1971; DeVietti et al., 1974; Mayse \& DeVietti, 1971). Since we used FS to motivate performance, our training paradigm was poorly adapted for the study of such effects. Nonetheless, it seemed worthwhile to test whether the discriminable effects of FS + ECS differed from those of ECS alone in our paradigm.

\section{Method}

Pinel showed that FS modified the convulsion produced by 
ECS; changes in the convulsion were most pronounced with severe and prolonged FS pretreatments. Hence, we placed our rats in a $7 \times 9 \times 11$ in. Lucite compartment and applied a $2.5-\mathrm{mA}$ intermittent $60-\mathrm{Hz}$ shock for $30 \mathrm{sec}(30 \%$ duty cycle). The rats were then removed from the compartment, earclipped, and given ECS as rapidly as possible; the interval between FS termination and ECS was 10-15 sec.

One group of six rats was trained as in Experiment II, using a 3-week training cycle and a $24-\mathrm{h}$ interval between FS + ECS and training. A second group of three rats was trained as in Experiment $I$, using a 3-day cycle and a 10-min interval between FS + ECS and training. A control group was trained with the 3-day cycle using FS-only as the treatment and a 10-min interval.

\section{Results and Discussion}

The control group $(\mathrm{N}=3)$ failed to discriminate the sequelae of FS within 60 sessions. Rats trained 10 min after FS + ECS discriminated the postictal state with the same rapidity as did the comparable group in Experiment I. Mean STCs were 5.6 vs. 5.1 and mean first-trial errors were 6.8 vs. 7.5.

None of the six rats trained $24 \mathrm{~h}$ after FS + ECS reached criterion within 40 sessions, whereas two out of six rats had shown criterion performance with ECS alone in Experiment II. Mean first-trial errors were similar in the two groups (15.7 vs. 18.0$)$, and ANOVA applied to the learning curves failed to show significant differences.

Our procedures differed substantially from those of DeVietti, in that we used a longer interval between FS and ECS, a more severe footshock and repeated FS + ECS treatments. We failed to find evidence that FS pretreatment enhanced the SDL effects of ECS, and the only trends in the data were in the opposite direction. Hence it appears that the effects of ECS responsible for our results differ substantially from the effects of FS + ECS which underlie his findings.

\section{GENERAL DISCUSSION}

The results can be summarized as follows: Learning was substantially state dependent during the first few minutes after ECS, as indicated by rapidly acquired differential responding. The degree of SDL attenuated rapidly during the $60 \mathrm{~min}$ following ECS, although appreciable SDL was apparently still present $24 \mathrm{~h}$ after ECS. We failed to find evidence that ECS SDL effects lasted longer than $24 \mathrm{~h}$, that footshock preceding ECS would alter the SDL effects of ECS, or that the discriminable effects of ECS were completely interchangeable with those of any tested drug.

There are at least two ways in which drug SDL and ECS SDL may be related to one another. First, ECS SDL may be mediated by unknown biochemical changes in the brain produced by ECS which achieve discriminative control via the same mechanisms as do drugs. Alternatively, discriminative control may result directly from brain dysfunction present during the postictal period which may be unrelated to biochemical sequelae of ECS. These and other postulated mechanisms for SDL have been previously discussed in the literature (Overton, 1973), and available data do not allow us to choose between these theories. The major contribution of the present studies is to provide a better definition of the time course of ECS SDL effects.

ECS might provide a usable preparation for the study of SDL in human subjects, as it is repeatedly administered to certain psychiatric patients. This would avoid the ethical problems associated with repeated administration of high doses of drugs. Although patients who receive ECS are generally psychotic, SDL discrimination studies utilizing the postictal period in such patients might provide useful data.

\section{REFERENCES}

Chorover, S. L., \& Deluca, A. M. Transient change in electrocorticographic reaction to ECS in the rat following footshock. Journal of Comparative and Physiological Psychology, 1969, 69, 141-149.

Davis, J. W., Thomas, R. K., \& Adams, H. E. Interactions of scopolamine and physostigmine with ECS and one trial learning. Physiology and Behavior, 1971, 6, 219-222.

DeVIETti, T. L., \& LARSON, R. C. ECS effects: Evidence supporting state-dependent learning in rats. Journal of Comparative and Physiological Psychology, 1971, 74, 407-415.

DeVietti, T. L., Mayse, J. F., \& Morris, L. W. Footshock/ECS induced state-dependent learning in rats: Parametric evaluation of ECS intensity and time of testing. Learning and Motivation, 1974, 5, 70-79.

Edw ARds, A. L. Statistical methods. New York: Holt, Rinehart and Winston, 1967.

Gardner, E. L., Glick, S. D., \& Jarvik, M. E. ECS dissociation of learning and one-way cross-dissociation with physostigmine and scopolamine. Physiology and Behavior, 1972, 8, 11-15.

Huang, J. T. Amphetamine and pentobarbital effects on the discriminative response control by deprivation of rapid eye movement sleep (REMS). Federation Proceedings, 1973, 32, 786. (Abstract)

Kesner, R. P., \& D'Andrea, J. Proactive changes in level of activity as a function of footshock and electroconvulsive shock treatments. Psychonomic Science, 1972, 28, 161-162.

Mayse, J. F., \& DeVietti, T. L. A comparison of statedependent learning induced by electroconvulsive shock and pentobarbital. Physiology and Behavior, 1971, 7, 717-721.

McIntyre, D. C., \& Reichert, H. State-dependent learning in rats induced by kindled convulsions. Physiology and Behavior. 1971, 7, 15-20.

Nielson, H. C., \& Fleming, R. M. Effects of electroconvulsive shock and prior stress on brain amine levels. Experimental Neurology, 1968, 20, 21-30.

Oris, L. S. Drive conditioning: Fear as a response to biogenic drive stimuli previously associated with painful stimulation. American Psychologist, 1956, 11, 397. (Abstract)

Overton, D. A. State-dependent learning produced by depressant and atropine-like drugs. Psychopharmacologia, $1966,10,6-31$. 


\section{2}

\section{OVERTON, ERCOLE, AND DUTTA}

Overton, D. A. Discriminative control of behavior by drug states. In T. Thompson and R. Pickens (Eds.), Stimulus properties of drugs. New York: Appleton-Century-Croft, 1971. Pp. 87-110.

Overton, D. A. State-dependent learning produced by addicting drugs. In S. Fisher and A. Freedman (Eds.), Opiate addiction: Origins and treatment. Washington, D.C: Winston, 1973. Pp. 61-75.

Overton, D. A. Experimental methods for the study of statedependent learning. Federation Proceedings, 1974, 33, 1800-1813.

PECK, J. H., \& ADER, R. Illness-induced taste aversion under states of deprivation and satiation. Animal Learning \& Behavior, 1974, 2, 6-8.
Pinel, J. P. Disruption of ECS-induced seizures in rats by antecedent footshock. Communications in Behavioral Biology, 1971, 6, 79-85.

Thompson, C. I., \& Neely, J. E. Dissociated learning in rats produced by electroconvulsive shock. Physiology and Behavior, 1970, 5, 783-786.

WiEnER, N. E. Electroconvulsive shock induced impairment and enhancement of a learned escape response. Physiology and Behavior, 1970, 5, 971-974.

(Received for publication November 10, 1974; revision received November 28,1975 .) 